\title{
Lighting conditions as the occupational health related issue - case study
}

\author{
Luiza Dębska ${ }^{1 *}$, Anita Białek ${ }^{1}$ \\ ${ }^{1}$ Faculty of Environmental Geomatic and Energy Engineering, Kielce University of Technology, 25- \\ 314 Kielce, Poland
}

\begin{abstract}
The paper deals with the important element of proper lighting conditions at a workplace. The case study has been focused on the intelligent building "Energis" of Kielce University of Technology, where the experimental tests took place. Several groups of volunteers filled in the questionnaires related to their subjective feelings of lighting conditions in lecture rooms at different seasons. Simultaneously, precise measurements of lighting intensity were carried out. The comparison of the expressions of the room users and the measurements enabled to draw conclusions about the conditions provided in the intelligent building related to lighting. The study provides valuable information of lighting conditions in the modern, intelligent buildings which are more and more common throughout the world and serve various purposes such as office, educational or other public utility buildings.
\end{abstract}

\section{Introduction}

Daylight and artificial lighting is one of the basic elements of the working environment in a workplace. It is a factor which has a significant impact on comfort, productivity and quality of work, and above all on its safety. Illumination enables a worker to perform his duties without feeling tired or having to use excessive strain on his eyes.

Both excessive light and not enough light can have serious consequences for our health. Not only for our eyesight. A person experiences visual discomfort by the over brightness of general illumination, the appearance in the field of vision of a light source with a brightness significantly different from the general illumination, and flicker - a frequently changing light level. The lack of proper light intensity affects the number of mistakes made and increases the risk of accidents at work [1]. At the same time, it reduces the level of concentration and efficiency of the employee.

The requirements for the level and uniformity of illuminance of the visual task area, depending on the type of interior and visual task, are given in the tables annexed to EN 12464. The lighting regulations for a particular workplace depend on the room in which the employee is working and the type of work that is being carried out. The light requirements of an employee on a warehouse floor are therefore different from those of an office worker using a monitor. According to the regulations, light intensity is measured in [lx]. Depending

\footnotetext{
*Corresponding author: ldebska@tu.kielce.pl
} 
on the activity performed by the worker, the range of correct illuminance is from 200 to 1500 [lx]. The required illuminance values for education rooms: classrooms - 300 [1x], meeting rooms and conference rooms - 500 [1x], reading rooms - 500 [1x] [2].

An important aspect, right from the design stage, is the level and distribution of lighting in the workplace environment. The standard [2] gives the required illuminance levels and uniformities for the task field, its immediate surroundings as well as the background, with a minimum width of $3 \mathrm{~m}$. Lighting affects the comfort a person feels. To reduce discomfort, it is particularly important to avoid situations with excessively bright lighting that produce glare. Places with too much light contrast cause eye fatigue due to constant accommodation of the eye. Conversely, when there is too little light or low contrast, it results in a monotonous working environment and a negative impact on the human body. The quality of light in the field of vision triggers the adaptive mechanisms of the eye, creating an image on the retina. Properly balanced adaptive lighting is required to improve, among other things, visual acuity. In order to assess the state of illumination of a workplace, it is necessary to verify the following [3]:

1. is the illuminance of the work surface $\mathrm{E}_{\text {medium }}[\mathrm{lx}]$ adequate for the work being performed?

2. the uniformity of illumination of the work surface in question, the entire room, and the passageways leading to the workplace,

3. that there are no factors distracting the eyesight, and that the arrangement of artificial lighting and windows is appropriate to ensure visual comfort?

When examining and diagnosing the state of lighting in a room, the light efficiency measured after a set period of time should also be taken into account. New light sources usually have a higher luminous efficiency than required because the lamps degrade over the years. Many lighting installations are also suffering from inadequate maintenance and therefore the standards assume wear and tear and a reduction in luminous efficiency of 20 $30 \%$ as a function of time [3].

Nowadays, when designing smart buildings, a lighting control and regulation system is introduced to reduce the cost of electricity demand. The combination of manual control (using switches and dimmers) and automatic control (using timers, motion sensors and light sensors) definitely shows savings in the operation of the system [3].

The market potential for intelligent lighting is growing rapidly. It is dictated by economics, wide range of applications, functionality and comfort of use. And today, optimal lighting control is a reality, providing measurable savings and, above all, a new quality of comfort [3].

An analysis of the literature review provided information about research conducted in the workplace and about different light intensity values, either conducive to employee satisfaction or not. The first such article is written by Idkhan \& Baharuddin [4] who conducted a study on 60 students undergoing apprenticeship in the laboratory of the Faculty of Mechanical Engineering. The aim of the study was to learn about the thermal sensations of the respondents and the impact of light intensity on the work performed by students between 7:00 - 12:00 and 13:00 - 16:00. The methods that the authors of the study used in the study were questionnaires, a lighting measurement meter and a digital thermometer. The results showed that the thermal comfort was achieved at the temperature of $30.44^{\circ} \mathrm{C}$ and the value of the light intensity was 422.14 [1x]. The conclusions presented by the authors show that the obtained parameters deviate from the standard range, which may contribute to a reduction in productivity at work. Bellia et al [5] presented a study to find out whether light and colour can affect the termination of people in a room. Therefore, the authors tested two types of lighting - warm $(3,000)$ and $\operatorname{cool}(6,000 \mathrm{~K})$ in an air-conditioned room for 163 people, where the lighting intensity value was 300 [1x] for $20^{\circ} \mathrm{C}$ and $25^{\circ} \mathrm{C}$ temperatures, people feel more comfortable with heat. Kussmaul, Peri \& Boyd [6] conducted a study in facilities for the care of the elderly in New Zealand, taking into account primarily the impact of internal 
factors on the perception of thermal discomfort by employees or deterioration of health or concentration that may have a negative impact on the quality of work. The study of the authors of the work consisted in checking whether the environmental parameters such as temperature, humidity, noise and lighting meet the standards for the work performed in nurses' offices and in resident waiting rooms. Measurements were taken continuously for 24 hours in the nurses 'offices and 12 hours in the residents' waiting rooms. From the obtained results, it was obtained that the temperature and light intensity do not meet the applicable standards, unlike noise and humidity, which are within the scope of international standards. Dianat, Vahedi \& Dehnavi [7] analyzed three production plants in terms of noise, light intensity and temperature. Out of 130 jobs, questionnaires were received and the necessary microclimate measurements were made. From the obtained measurements and responses of people working in these plants, information was obtained that in nearly half of the workplaces, the conditions in them did not meet the expectations of the employees, including parameters that significantly deviated from the recommended standards. In addition, it was confirmed that by failing to meet the lighting and noise standards, they contributed to the deterioration of employees' efficiency in the surveyed establishments. Another, but equally interesting idea was demonstrated by the authors of the study, Kombeiz \& Dietl, [8] who examined the intensity of light as a social factor that could influence the positive assessment of other people in the workplace. 164 people participated in this study. The perceived comfort of lighting in the room and the assessment of other people with the warm colour of the light were assessed. It turned out that warm light has a positive effect on the perception of other people in the company. Baniya et al. [9] investigated the feeling of comfort of 16 people in the workplace with light intensity equal to 500 [lx] at 25 and 20 temperature. For 10 minutes, volunteers were in a room where the temperature bar was first $2700 \mathrm{~K}$, then $4000 \mathrm{~K}$ and $6200 \mathrm{~K}$. From the obtained results, the respondents defined thermal comfort for $4000 \mathrm{~K}$, i.e. between warm and cool light.

Based on the analysis of the available literature, it can be seen that there is very little research related to the intensity of light and the well-being of people in intelligent buildings in Central and Eastern Europe (as opposed to thermal comfort tests in such buildings - e.g. $[10,11]$. This paper aims to provide information and knowledge whether intelligent buildings meet indoor lighting standards, because people are often dissatisfied with the lighting of their workplaces. The topic is important because it is about specifying the requirements of employees and increasing their efficiency at work.

\section{Materials and methods}

The research was carried out in an intelligent building that belongs to the Kielce University of Technology, called "Energis". The building was put into use in 2012. Inside, there are 22 classrooms, offices, laboratory facilities and rooms for lecturers. The total usable area is $5,121.24 \mathrm{~m}^{2}$. The entire facility is an example of an intelligent building in which renewable energy sources are used, as well as a control and regulation system for ventilation, heating and cooling and lighting systems (Fig. 1). 


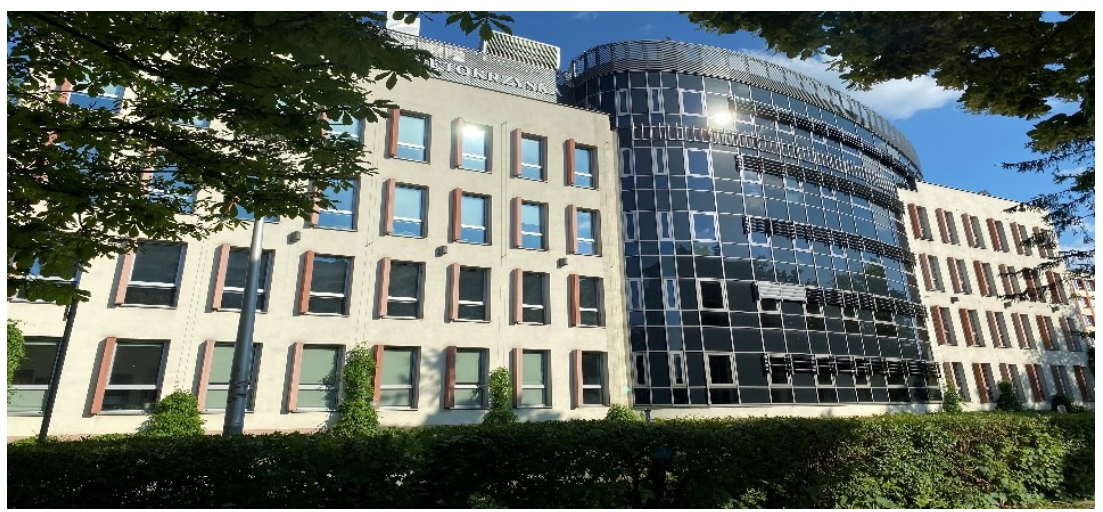

Fig. 1. Intelligent building "Energis", Kielce University of Technology.

The study was conducted with the use of questionnaires and the Testo 400 meter. In the questionnaires, students assessed the intensity of light (whether it is good or not), their feelings and presented their well-being in the rooms. On the other hand, the testo meter, apart from retrieving information about the amount of light intensity, also performs measurements: temperature, humidity, air velocity, etc. The accuracy as specified by the meter manufacturer for lighting intensity probe according to the catalog is $+/-0.1$ [lx]. The meter and light intensity probe (red colour) are shown in Figure 2.

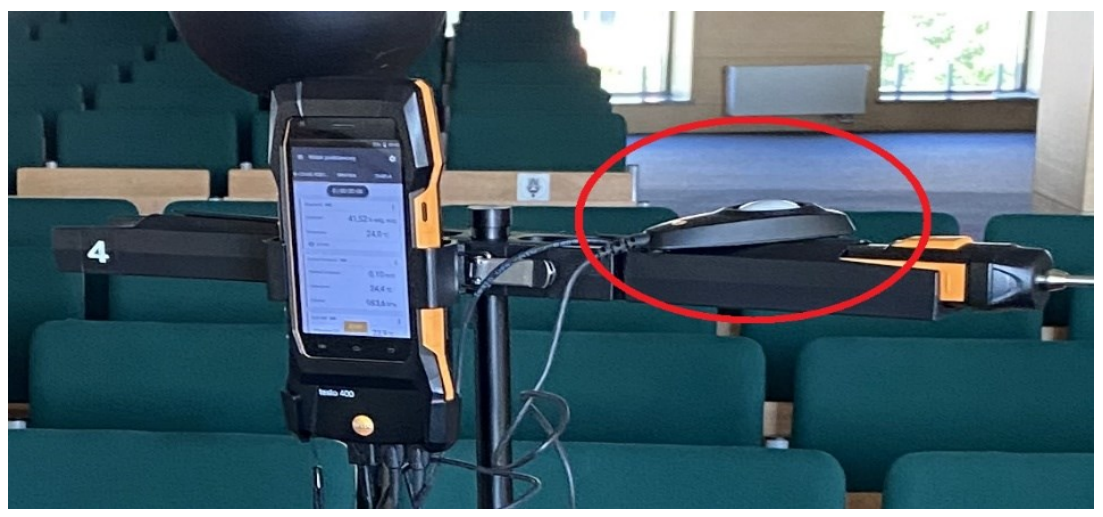

Fig. 2. Testo mester and light intensity probe.

The examination was as follows, firstly, the Testo meter was placed in the center of each examination room. Secondly, in the meantime, the students completed the questionnaires. After 15 minutes, when all parameters had stabilized, they were saved and the questionnaires were collected. The study was conducted in 12 classrooms at different time intervals from October 12, 2020 to June 12, 2021. In total, 157 people aged 18-28 participated in the survey, where women constituted $36 \%$ of the attendance, and men $64 \%$.

\section{Results and discussion}

The lighting parameters obtained in 12 rooms (somewhere tested more than once) and the compliance with the EN 12646 standard are summarized in Table 1. 
Table 1. Summary of the obtained lighting results and their compliance with the EN 12646 standard.

\begin{tabular}{|l|c|c|c|}
\hline & $\begin{array}{c}\text { Light } \\
\text { intensity } \\
{[\mathrm{lx}]}\end{array}$ & $\begin{array}{c}\text { Room } \\
\text { volume } \\
{\left[\mathrm{m}^{3}\right]}\end{array}$ & $\begin{array}{c}\text { Compliance with the } \\
\text { standard }\end{array}$ \\
\hline Room 1 & 313 & 471 & Yes \\
\hline Room 2 & 300 & 471 & Yes \\
\hline Room 3 & 288 & 471 & No \\
\hline Room 4 & 429 & 471 & Yes \\
\hline Room 5 & 282 & 471 & No \\
\hline Room 6 & 424 & 471 & Yes \\
\hline Room 7 & 644 & 279 & Yes \\
\hline Room 8 & 898 & 279 & Yes \\
\hline Room 9 & 158 & 183 & No \\
\hline Room 10 & 120 & 1377 & No \\
\hline Room 11 & 185 & 471 & No \\
\hline Room 12 & 477 & 471 & Yes \\
\hline
\end{tabular}

Based on the data presented in Table 1, it can be seen that as many as five rooms do not meet the lighting requirements included in the standard, because these values are less than $300[1 x]$. Further analysis will present the actual feelings of people, which will make it easier to check whether the values presented in the standard are well matched to people's expectations.

Figure 3 presents the general assessment of lighting in the halls of the "Energis" building according to the surveyed groups of students (Light assessment vote - LAV).

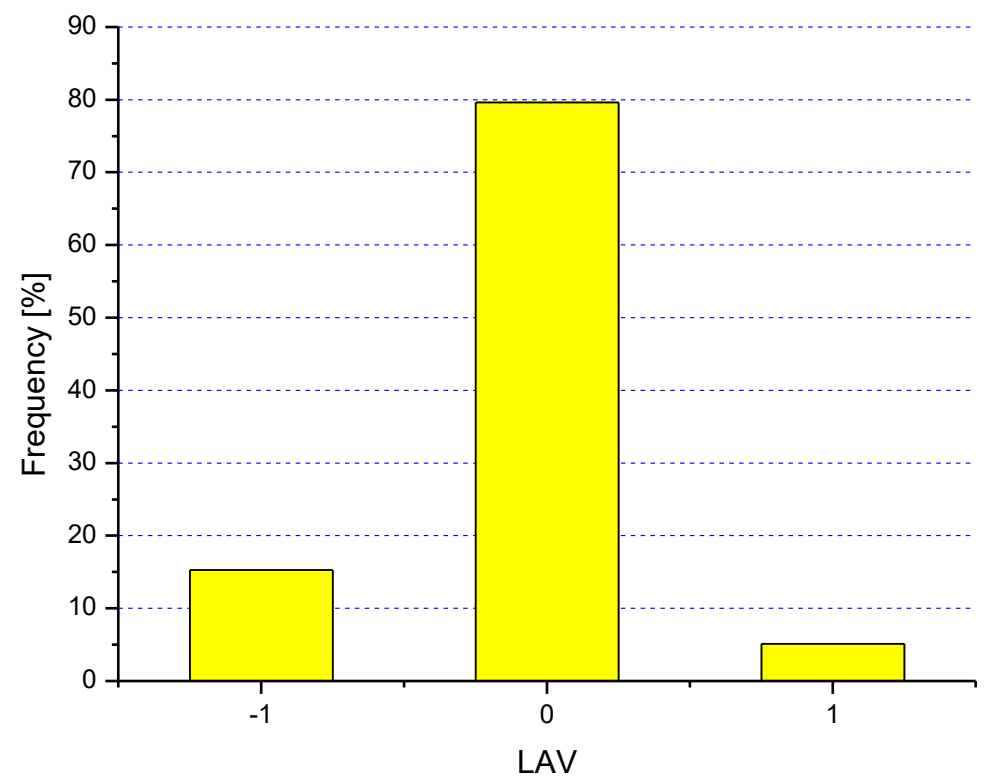

Fig. 3. Assessment of lighting in lecture halls according to students: -1 - too weak; 0 - suitable; 1 - too strong. 
The general observations of the group regarding lighting showed that the respondents described them in the rooms as appropriate (0), thus constituting $79.62 \%$ of people. The rest of the group, i.e. $15.29 \%$ of people, assessed the lighting as too weak (-1) and $5.10 \%$ that the lighting was too strong (1). Based on the above results, it can be concluded that about $80 \%$ of people are satisfied with the lighting intensity in the rooms of the building under study and these people assess it well. Referring to the answers of the respondents from Figure 3, in which their general feelings of lighting from all rooms were presented, the next analysis will concern their average feelings, but separately, i.e. from each room - will be marked as average lighting assessment vote in short LAV (a). Figure 4 shows the intensity of illumination and the average lighting assessment vote (LAV-a) of people in each room tested.

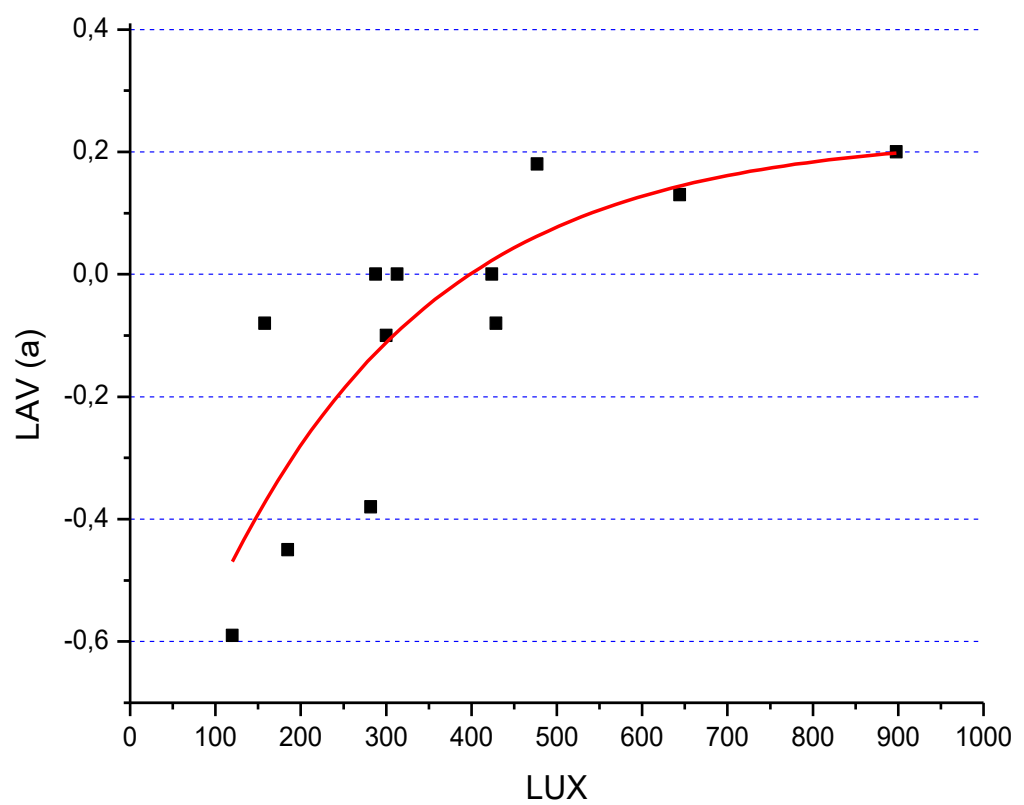

Fig. 4. The light intensity and the average lighting assessment vote of people in the rooms.

Depending on the tested rooms and their lighting, based on Figure 4, it can be noticed that people assessed the light intensity in the rooms as weak. Their dissatisfaction concerns lighting below $430[\mathrm{~lx}]$. This can be seen in particular in room 10 where the light intensity was $120[\mathrm{~lx}]$ and where the lowest average human perception was -0.6 . The highest satisfaction with lighting was in room 8 , where the light intensity was 898 [1x] and the average score for this group was 0.20 . This means that people prefer a light that is strong and intense. This is shown by the line which stabilizes from the value of 600 [1x]. Taking into account the answers of the respondents, it can be concluded that the standard which assumes the value of $300[1 \mathrm{x}]$ for classes and above does not meet the minimum expectations of people. From these results, the information was obtained that this value should be increased to a minimum of 430 [1x]. For further analysis, the mean related to the lighting rating (which was calculated and presented in Figure 4) and the averages resulting from the general well-being of people in the rooms were compared. For this purpose, the respondents answered a question in which they assessed their well-being as: very good $(+2)$, good $(+1)$, indifferent $(0)$, bad $(-1)$ and very bad (-2). On this basis, the average general feelings of people were calculated. Figure 5 presents the average lighting assessment vote in each room and the average rating of wellbeing in the each room. 


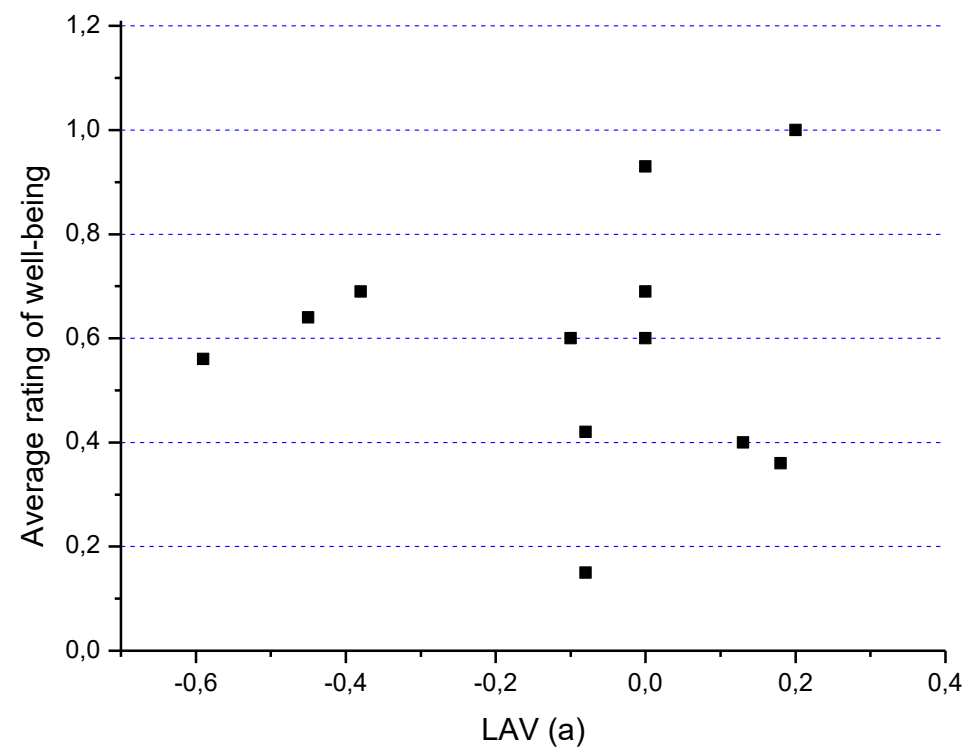

Fig. 5. The average lighting assessment vote (LAV-a) and average rating of well-being in the each room.

Based on the results obtained, it can be concluded that lighting does not affect the general feeling of well-being by the respondents. If it were so, the average would be as high as possible.

\section{Conclusions}

Summarizing the obtained results, it can be stated that people in the Energis the intelligent building are generally satisfied with indoor lighting, accounting for a total of approx. $80 \%$ of people who consider it appropriate. On the other hand, Figure 5 shows the actual satisfaction with lighting in the respondents' opinion, starting from 430 [1x] and begins to stabilize when the value reaches about $900[\mathrm{~lx}]$. This fact contradicts the standard, which assumes that the minimum illumination can be equal to 300 [1x]. The studies that have been carried out have definitely shown that such a value is not satisfied by people and the values in the norm should be changed to higher. Using the proposed research and the obtained conclusions, it is possible to implement such a change to higher illuminance for various industries. Increasing the value of lighting intensity in offices or in production halls could improve the working conditions by increasing productivity, creativity, focus and improving the vision of the eye, which would not have to work so hard in stronger light. Taking this into account an additional conclusion is also the fact that more lighting tests should be carried out at workplaces and the opinion of people should be taken into account more often (e.g. in the form of questionnaires) in order primarily to determine whether this lighting is suitable for these people and whether its intensity is positive or not negative and whether it can negatively affect their well-being.

\section{References}


1. Regulation of the Minister of Labour and Social Policy of 26 September 1997 on general rules of safety and hygiene at work, Journal of Laws of 2003. No. 169, item 1650 as amended. - par. 26 (2)

2. EN 12464-1:2012, Light and lighting - Lighting of workplaces - Part 1: Indoor workplaces (2012)

3. A. Wolska, Central Institute for Labor Protection - National Institute: Lighting and accidents at work, Work Safety - Science and Practice 9/2003 pp. 13-15 (2003)

4. A. M. Idkhan, F. R. Baharuddin, Int. J. Environ. Eng. Educ., vol. 1, no. 2 (2019) https://doi.org/10.5281/zenodo.3477838

5. L. Bellia, F. R. d'A. Alfano, F. Fragliasso, B. I. Palella, G. Riccio, En. \& Build., 231 (2021) https://doi.org/10.1016/j.enbuild.2020.110570

6. J. Kussmaul, K. Peri, M. Boyd, Workplace environment for nurses and healthcare assistants in residential aged care facilities in New Zealand. Aus. J. of Adv. Nur., 36, 4 (2019)

7. A. Vahedi, S. Dehnavi, Inter. J. of Ind. Erg., 54, pp. 26-31 (2016)

8. O. Kombeiz, E. Dietl, Erg., 62, pp. 995-1007 https://doi.org/10.1080/00140139.2019.1608316

9. R. R. Baniya, E. Tetri, J. Virtanen, L. Halonen, Ind. \& Built Envir., 27, 3 (2018) https://doi.org/10.1177\%2F1420326X16673214

10. Majewski G., Orman Ł.J., Telejko M., Radek N., Pietraszek J., Dudek A., Energ., 13(8), 1973, (2020) https://doi.org/10.3390/en13081973

11. Majewski G., Telejko M., Orman Ł.J., Preliminary results of thermal comfort analysis in selected buildings, Proc. of Conf. on Interdisciplinatry Problems in Environmental Protection and Engineering (EKO-DOK), Poland, E3S Web of Conferences, 17, 00056, (2017) https://doi.org/10.1051/e3sconf/20171700056 